\title{
Socio-Cultural, Economic and Environmental Impact of Tibetan Refugee Settlement on Host Community in Pokhara
}

\author{
Santosh Kumar Gurung ${ }^{1}$, Bal Ram Bhattarai ${ }^{2}$, Shanti Devi Chhetri ${ }^{3}$, Anisha Bataju ${ }^{4}$, Ganga Ghale
} Abstract

The study attempts to empirically investigate and assess the socio-cultural, economic and environmental impact of the refugee settlements on the local host community who are living around the Tashi Pakhiel Tibetan camp located in Hemja, Kaski district. A questionnaire survey was undertaken to collect opinion of 500 host community members on the issue. The findings reveal that there exists social harmony, mutual co-existence, and bonding between the Tibetan refugees and local residents of Hemja. The two communities involve in social exchange and participate in social events of each other. The social acceptance is revealed from the fact that the practice of intermarriages between the communities is also prevalent. The Tibetan refugee camp is found not to adversely impact the host community culture. Similarly, the refugee settlement has not brought any adverse effect on the local environment. The basic services and facilities like education and health is available on equitable basis to both the communities. Finally, the economic interaction between the communities has resulted in mutually beneficial economic condition for both in terms of increased business and employment opportunities. Moreover, the economic benefits to the host community are found to be relatively higher as compared to the benefits received by the refugees.

Keywords: Environmental Impact, Tibetan refugees, Socio-cultural, Economic

\section{Introduction}

The refugee issue is as complex as its causes, solutions and effects. Obviously, it is a clear humanitarian, moral and development issue facing humanity. Millions of people get displaced globally as a result of conflict, violence, and human rights violations. It is generally recognized that there are humanitarian, political, security, and development challenges during the time of displacement and the period after durable solutions have been identified, either in the home country, a neighboring state, or elsewhere. The world refugee problem is caused by a variety of reasons; factors and forces.

The responses of host countries to these mass influxes have varied greatly, both between states and, for single governments, over time and by refugee group. Some governments have received refugees with generosity, providing them with assistance and guaranteeing their safety. Others have tried to prevent refugees from entering or have treated them harshly, restricting their movements and even endangering their safety (Jacobsen 1996, Aristide 1992). The majority of countries hosting large numbers of refugees are developing and poor countries. Developing countries that host refugees for protracted periods can experience long-term, economic, social and environmental consequences (UNHCR Standing Committee, 1997). Nepal is also not an exception of the refugee problem. Specifically, Nepal has faced problems associated with Tibetans and Bhutanese refugees.

An official record of the Government of Nepal confirms that 12,540 Tibetans living in different parts of Nepal, however the actual number of Tibetan refugees in Nepal at present is estimated to be around 20,000 as the government has not updated the record since 1993. The Tibetan refugees living in Nepal are dispersed in over

Lecturer, School of Business, Pokhara University 
21 districts of the country in Tibetan refugee camps (NUCRA, 2010). In 1960, upon the request of Nepalese authority, the International Committee of the Red Cross (ICRC) established emergency relief camps. In a similar vein, the Nepalese government, with the assistance of funds donated by the office of the United Nations High Commissioner for Refugee (UNHCR) also set up refugee shelter homes. Till the mid-1980s, the Nepalese government welcomed the Tibetan Refugees with open hands as the latter were not perceived as a threat to Nepalese diplomatic relations with China (IRIN, 2013).

The impact of refugees on host communities has largely been assumed to be negative. On the other hand some also believe that the influx of the refugees create a new context in which hosts devised strategies to gain access to incoming resources and to maintain access to their own resources. It must also be acknowledged that refugees could have a positive impact on the economy by contributing to agricultural production, providing cheap labor and increasing local traders' income from the sale of essential foodstuffs. Some local populations benefit from access to schools, clinics and other social facilities built by the international community (Beth, 1999).

The presence of refugees compounds the already prevailing economic, environmental, social and difficulties in these countries. The presence of refugees, and demands on the already severely strained economy, services and infrastructure add to the extreme hardship affecting the local populations. In many instances, refugees become an added impediment to, or risk jeopardizing, the development efforts of the host country. Their negative aspects may be felt long after a refugee problem is solved; for example, the damage to environment is a process and does not end with the repatriation of refugees (UNHCR Standing Committee, 1997)

The presence of refugees also contributes to the creation of employment benefiting the local population, directly or indirectly. While it is recognized that there may be some "positive" aspects to the impact of a refugee influx on the economic life of a host country, the large-scale presence of refugees invariably constitutes a heavy burden for receiving countries, particularly LDCs (UNHCR Standing Committee, 1997). In this context, the study attempts to empirically investigate the social, economic and environmental issues associated with Tibetan refugees settlement in Nepal. Hence, the general objective of the study is to empirically investigate and assess the socio-cultural, economic and environmental impact of the refugee settlements on the local host community who are living around the Tashi Pakhiel Tibetan camp located in Hemja, Kaski district.

\section{Literature Review}

Literature on issues relating to impacts of refugee camps on host communities has received equally limited attention. Maystad \& Verwimp, 2009) claims that knowledge and literature on these issues has not improved much since the analysis of Chambers from 1986. Responding to these claims is this research aiming at contributing to the gap in knowledge of the complexity of impacts on host communities by refugee camps, and how this further affects the relationship between hosts and refugees.

Sanjugta (2003) explored the socio-cultural impact of refugees on developing or host communities. This study encompasses the issues of social or relational as well as religious, linguistic and ethnic character which arise when large groups of refugees arrive within a given host community. The study finds that the socio-cultural impact of refugees on the receiving community can occur simply through their presence, in that they can play a role in altering the ethnic balance of the host community, and if the influx is sizeable, pose a threat to the cultural values and norms of the nation.

Werker (2007) in a case study of refugees in Uganda has made the following observations about the Kyangwali refugee camp economy as it tends to give refugees more choice on their settlement relative to many other countries in Africa. He argues that the economy in the settlement is fairly complex. Incomes are produced through a variety of means. Most refugees are either engaged in agricultural production or are receiving food 
rations from charity. Minority of refugees has businesses in the settlement, ranging from small stalls at the weekly market to shops or teahouses in the main trading center. Whitaker (2000) examines the implications of the refugee presence for host communities in Tanzania. Over the years, there have been many calls for strategies linking refugee relief with local development, but a number of factors have impeded their effective integration, including lack of donor support, weak coordination between refugee and development bureaucracies, and increasing numbers of refugees (Betts 1981, 1984; Gorman 1994 see Whitaker 2000). Despite the common assumption that refugees represent a problem or burden (Harrell-Bond 1986), it is clear that refugee migrations bring both costs and benefits to host countries (Kuhlman 1994, Sorenson 1994, J. Baker 1995) as cited in Whitaker (2000). Refugees generally impose a burden on local infrastructure, environment, and resources, but they also provide cheap labour, expand consumer markets, and justify increased foreign aid.

Andrian (2005) in his study of Bonga camp in Ethiopia argues that the most obvious environmental impact of the refugee camp is deforestation, although he believes that this problem was already occurring before the refugees arrived in 1993 but it has increased because of the expansion of slash and burn agriculture into the near by hillsides, mainly for growing sorghum. He noted that both refugee and host people also rely on wood for fuel and construction, and there are high levels of hunting with traditional weapons anddogs.

Williams (1995) performed analysis that showed overall immigration impacts are largely neutral on the macroeconomic level. Another analysis that looked at immigration over a large sample of countries found a positive impact from the diversity of skilled immigration on both the incomes and productivity levels among the richer nations. Among the more detailed-level conclusions of Williams were that immigration does not lead to an increase in the unemployment rate, refuting one of the main criticisms that immigrants and refugees steal native jobs. She furthermore found that immigrants are net contributors to federal and local government tax revenues in the long-run. However, when the economic impacts of refugees are analyzed on a local or regional level, the positive impacts are more significant.

Refugees are more likely to be entrepreneurial and enjoy higher rates of successful business ventures compared to natives. In many places with large concentration of refugees, there are ethnic restaurants and grocery stores that serve not only immigrants, but also native residents. The connections and social networks of refugees back in their originating countries facilitate the generation of transnational businesses such as international trade, investment, and tourism (Hohn, 2012). The nature of impacts of refugee influx and camp establishments on host communities are many and diverse. Exact knowledge of these impacts and how they affect host communities is nevertheless lacking according to researchers of the field such as Chambers (1986) and Maystadt and Verwimp (2009). Chambers (1986) explains likely cost and benefits for hosts in a refugee-hosting situation into three groups of hosts; surplus famers, subsistence farmers and labors with negligible or no land. Further on Chambers offers five dimensions of analysis of the cost benefit relationship which is accordingly dependent upon food/ land, labor/wages, services, common property resources (CPRs) and economic development. World Bank (2011) supports Chambers arguments that social services often are improved in refugee hosting communities, referring to experiences in Mexico in the early 1990s. Similarly UNHCR is arguing that health and sanitation services improve in refugee hosting communities.

Economic development within host communities as a result of refugee presence can vary a great deal. As expressed by Alix-Garcia and Saah (2009) through a World Bank economic review discussing the economic impacts of refugee camps on host communities which can both be positive and negative. New market opportunities for locals to sell local merchandises may have a positive effect for some, while at the same time competition over already scarce resources may bring challenges for others. Cheap labor, trading, framing etc. 
can stimulate economic development of the hosting area. Infrastructural improvements such as new roads, access to markets and goods can also raise economic activity. Population growth through non-refugee migration to the area due to opportunities accompanied by the refugee presences may also impact in different ways. The nature of the economic development will nevertheless depend on official policies and interventions of the hosting country (Chambers 1986). This shows some of the complexity of possible impacts refugee influx may have on the economic as well as overall situation for people of host communities.

\section{Data and Methodology}

Quantitative approach has been employed in this study using descriptive and analytical research design. There are four Tibetan refugee settlements in operation in Pokhara among which the surrounding area of Tashi Palikheil camp of Hemja is the study area. The study is based on an area of $5 \mathrm{~km}$ radius of routine interaction between the refugee settlement and host community for in-depth analysis of impacts encompassing an area of $5 \mathrm{~km}$ covering 4 wards in one municipality. All the local people residing in vicinity of the Tashi Palkhiel Tibetan camp located in Hemja, Kaski comprise the universe of study and a total of 500 samples has been taken purposively following stratified sampling procedure. The stratification criteria was gender, ethnicity, education, age and economic activities. The eligibility for being selected as sample unit is respondents should be local people with permanent residence who are 16 and above. A semistructured questionnaire was used as primary survey instrument. The questionnaires used in the study were self-administered. To facilitate ease on understanding, questionnaire was distributed in Nepali language.

Descriptive statistics like frequency, cross-tabulation and arithmetic mean have been computed. Parametric inferential analysis using Chi-square test has been employed for drawing inferences. Moreover, Cramer's V has been calculated to examine the degree of association between the variables used in the study.

\section{Empirical Analysis}

\subsection{Description of the Respondents}

The study is based on survey local people residing in vicinity of the Tashi Palkhiel Tibetan camp. The unit of analysis comprise of individuals of households in the study area, willing to participate in the survey after getting informed consent. Table I exhibits the socio-demographic profile of the respondents in the host community. The gender-wise distribution reveals that the sample is representative of both male and female. Similarly, the survey incorporates respondents of different age groups, however, a majority 53.2 percent of the respondents are of 25 to 50 age. The ethnic distribution depicts that Chhetri and Bhramin represent of 64.8 percent of the sample while remaining comprise of janajatis including Newar, Magar, and Gurung. A large majority of the host community people are found to be Hindus. They comprise of 95.2 percent of the respondents. Some Buddhists and Christians are also found to be residing in the host community. Hence, the sample is representative in terms of gender, age, ethnicity and religion.

Most of the households in the study area are found to have nuclear family structure with family size of 3 to 5 persons. It indicates that the influence of urbanization has changed host community family structure from traditional joint family prevalent in rural and sub-urban areas of Nepal. However, still 42 percent of the households in the area are found to live in joint family and 13.2 percent families have size of more than 7 members. Regarding years of residency, around 76 percent of the respondents have lived for a period of more than 15 years in the area. Therefore, the respondents should have interacted with the Tibetan refugees for a longer time period and hence should be in better position to offer opinion of impact of refugee settlement in the host community. The major occupations of the people in host community are business and agriculture. Only 12 percent are employed in different jobs while 6.4 percent are found to be unemployed. Regarding income level, most of the respondents are found to earn Rs. 10,000 to 25,000 per month. Only 8.2 
percent have monthly income of more than Rs 50,000. resided for more than 15 years in Hemja and are engaged Overall, majority of respondents are Bhramin or Chhetri, in business or agriculture.

male aged 25 to 50 years who live in nuclear family, have

Table I: Respondents' Profile

\begin{tabular}{|c|c|c|c|c|c|}
\hline Gender & Frequency & Percent & Age & Frequency & Percent \\
\hline Male & 262 & $52.4 \%$ & Below 25 & 98 & 19.6 \\
\hline \multirow[t]{2}{*}{ Female } & 238 & $47.6 \%$ & 25 to 50 & 266 & 53.2 \\
\hline & & & 51 to 75 & 115 & 23.0 \\
\hline Total & 500 & $100 \%$ & 75 and Above & 21 & 4.2 \\
\hline Ethnicity & Frequency & Percent & Religion & Frequency & Percent \\
\hline Bhramin & 157 & 31.4 & Hindu & 476 & 95.2 \\
\hline Chhetri & 167 & 33.4 & Christian & 7 & 1.4 \\
\hline Newar & 46 & 9.2 & Buddhism & 13 & 2.6 \\
\hline Gurung & 17 & 3.4 & Others & 4 & 0.8 \\
\hline Magar & 21 & 4.2 & & & \\
\hline Others & 6 & 1.2 & & & \\
\hline
\end{tabular}

\begin{tabular}{lcclcc}
\hline \multicolumn{1}{c}{ Family Size } & Frequency & Percent & \multicolumn{1}{c}{ Family Type } & Frequency & Percent \\
\hline Below 3 & 31 & 6.2 & Joint & 210 & 42.0 \\
3 to 5 & 294 & 58.8 & Nuclear & 280 & 56.0 \\
5 to 7 & 109 & 21.8 & Single & 10 & 2.0 \\
Above 7 & 66 & 13.2 & & & \\
\hline
\end{tabular}

\begin{tabular}{lccccc}
\hline \multicolumn{1}{c}{ Hemja Living } & Frequency & Percent & Income Level & Frequency & Percent \\
\hline Less than 5 yrs & 39 & 7.8 & Less than 10,000 & 116 & 23.2 \\
5 to 10 yrs & 43 & 8.6 & 10,001 to 25,000 & 167 & 33.4 \\
10 to 15 yrs & 40 & 8.0 & 25,001 to 50,000 & 64 & 12.8 \\
More than 15 yrs & 378 & 75.6 & More than 50,000 & 41 & 8.2 \\
\hline
\end{tabular}

Occupational Status

\begin{tabular}{lcclcc}
\hline \multicolumn{1}{c}{ Occupation } & Frequency & Percent & Occupation & Frequency & Percent \\
\hline Business & 141 & 28.2 & Unemployed & 32 & 6.4 \\
Student & 65 & 13 & Housewife & 47 & 9.4 \\
Farming & 120 & 24 & Others & 35 & 7 \\
Job holder & 60 & 12 & & & \\
\hline
\end{tabular}

\subsection{Influence of Refugee Settlement on Socio-cultural}

\section{Environment}

Table II presents the results of cross-tabulation, Chisquare test and Cramer's V used to analyze the association among socio-demographic characteristics of the respondents with their perception on whether the Tibetan refugee settlement has made impact on host community culture. The null hypothesis is there is no statistically significant association between socio-demographic features of the respondents and their perceived impact of Tibetan refugee settlement on host community. 
Table II: Host Community Opinion on Influence of Refugees Settlement on Local Culture

\begin{tabular}{|c|c|c|c|c|c|}
\hline & Impact & No Impact & Chi-Square & Sig. & Cramer's V \\
\hline \multicolumn{6}{|l|}{ Gender } \\
\hline Male & 6.9 & 93.1 & $6.464^{*}$ & 0.011 & 0.114 \\
\hline Female & 2.1 & 97.9 & & & \\
\hline \multicolumn{6}{|l|}{ Age } \\
\hline Below 25 & 6.1 & 93.9 & 2.930 & 0.403 & 0.077 \\
\hline 25 to 50 & 5.3 & 94.7 & & & \\
\hline 51 to 75 & 1.7 & 98.3 & & & \\
\hline Above 75 & 4.8 & 95.2 & & & \\
\hline \multicolumn{6}{|l|}{ Ethnicity } \\
\hline Bhramin & 6.4 & 93.6 & 3.522 & 0.833 & 0.084 \\
\hline Chhetri & 3.6 & 96.4 & & & \\
\hline Newar & 2.2 & 97.8 & & & \\
\hline Gurung & 0 & 100 & & & \\
\hline Magar & 4.8 & 95.2 & & & \\
\hline Thakali & 0 & 100.0 & & & \\
\hline Tamang & 0 & 100.0 & & & \\
\hline Others & 5.8 & 94.2 & & & \\
\hline \multicolumn{6}{|l|}{ Years of Stay } \\
\hline Below 5 yrs & 5.1 & 94.9 & 4.129 & 0.248 & 0.091 \\
\hline 5 to $10 \mathrm{yrs}$ & 9.3 & 90.7 & & & \\
\hline 10 to $15 \mathrm{yrs}$ & 0 & 100 & & & \\
\hline Above 15 yrs & 4.5 & 95.5 & & & \\
\hline \multicolumn{6}{|c|}{ Occupational Status } \\
\hline Business & 3.5 & 96.5 & 10.897 & 0.092 & 0.148 \\
\hline Student & 9.2 & 90.8 & & & \\
\hline Farming & 5.0 & 95.0 & & & \\
\hline Employee & 1.7 & 98.3 & & & \\
\hline Unemployed & 3.1 & 96.9 & & & \\
\hline Housewife & 0 & 100 & & & \\
\hline Others & 11.4 & 88.6 & & & \\
\hline
\end{tabular}

\begin{tabular}{|c|c|c|c|c|c|}
\hline \multicolumn{6}{|c|}{ Social Interaction by Income Status of Host Community } \\
\hline Below 10,000 & 1.7 & 98.3 & 3.953 & 0.267 & 0.101 \\
\hline 10,001 to 25,000 & 4.2 & 95.8 & & & \\
\hline 25,001 to 50,000 & 7.8 & 92.2 & & & \\
\hline Above 50,000 & 4.9 & 95.1 & & & \\
\hline
\end{tabular}

* means the test statistic is significant at $5 \%$ level of significance (p-value $<0.05)$

The results show that none of the Chi-square statistics except for gender are significant, hence, no significant difference is found among the host community regarding their view on impact of the refugee settlement on host community culture. Majority of the local respondents opine that there is no impact of the refugee settlement on host community culture. Specially, Gurung, Thakali and Tamang are of view that no any impact is observed. Relatively male students who have resided in the area for around 5 to 10 years and are Brahmins feel some impact is present.

\subsection{Influence of Refugee Settlement on Local Environment}

Table III exhibits the results of Chi-square test used to reveal association between socio-demographic variables of the respondents with their perceived environmental cleanliness maintained by the refugee settlement. None of the Chi-square statistics are statistically significant. Hence, no association is found between socio-demographic features of the respondents and their perception on environmental pollution due to the refugee settlement. In other words, the local respondents 
have similar opinion regarding environmental hygiene the respondents think that the Tibetan refugees have maintained by the refugee settlement. Majority of maintained environmental cleanliness.

Table III: Host Community Opinion on Influence of Refugee Settlement on Local Environment

\begin{tabular}{lccccc}
\hline & Yes & No & Chi-Square & Sig. & Cramer's V \\
\hline Gender & & & & & \\
\hline Male & 90.8 & 8.4 & 0.877 & 0.645 & 0.042 \\
Female & 89.1 & 10.5 & & & \\
\hline Age & & & & & \\
\hline Below 25 & 91.8 & 8.2 & 7.212 & 0.302 & 0.085 \\
25 to 50 & 88.3 & 11.3 & & & \\
51 to 75 & 90.4 & 7.8 & & & \\
Above 75 & 100.0 & 0.0 & & & \\
\hline Years of Stay & & & & & \\
\hline Below 5 yrs & 89.7 & 10.3 & 3.723 & \\
5 to 10 yrs & 83.7 & 16.3 & & & \\
10 to 15 yrs & 92.5 & 7.5 & & & \\
Above 15 yrs & 90.5 & 9.5 & & & \\
\hline Occupational Status & & & & & \\
\hline Business & 91.5 & 8.5 & 16.699 & \\
Student & 93.8 & 6.2 & & & \\
Farming & 93.3 & 6.7 & & & \\
Employee & 85.0 & 15.0 & & & \\
Unemployed & 81.2 & 18.8 & & & \\
Housewife & 87.2 & 12.8 & & & \\
Others & 85.7 & 14.3 & & & \\
* & & & & \\
\hline
\end{tabular}

${ }^{*}$ means the test statistic is significant at $5 \%$ level of significance (p-value $\left.<0.05\right)$

Overall, the results suggest that the Tashi Palkhiel settlement camp has not made adverse impact on the environment. The refugees have maintained environmental cleanliness, preserved natural resources and have not played role in environmental pollution. It means contrary to the findings of similar studies, the Tibetan camp at Hemja has been successful in preservation of the natural environment in their vicinity.

\subsection{Influence of Refugee Settlement on Economic Activities}

Table IV presents the association between socioeconomic characteristics of the respondents and their perception on economic benefits received by the host community due the refugee settlement. The Chi-square statistics is found to be significant only in case of religion and years of stay. It reveals that the view on whether the host community has received economic benefits in terms of increased business and employment opportunity is associated with religion and length of residency of the locals. The Chi-square value of $15.67(p<0.01)$ for the variable years of stay reveals that local residing in the study area for longer period of time perceive the local business and job opportunities have increased due to the refugee settlement. Similarly, the results reveal that Hindus and Christians have favorable view on economic benefits received by the host community due to refugee settlement. No association has been found in case of variables contact frequency, age, occupation and income level. 
Table IV: Opinion of Host Community about Influence of Refugees on Local Economy

\begin{tabular}{|c|c|c|c|c|c|}
\hline & Increase & No Increase & Chi-Square & Sig. & Cramer's V \\
\hline \multicolumn{6}{|c|}{ Contact Frequency } \\
\hline Frequently & 85.9 & 14.1 & 2.278 & 0.320 & 0.081 \\
\hline Sometimes & 91.2 & 8.8 & & & \\
\hline Rarely & 84.2 & 15.8 & & & \\
\hline \multicolumn{6}{|l|}{ Age } \\
\hline Below 25 & 81.6 & 18.4 & 3.309 & 0.346 & 0.082 \\
\hline 25 to 50 & 86.0 & 14.0 & & & \\
\hline 51 to 75 & 87.7 & 12.3 & & & \\
\hline Above 75 & 95.2 & 4.8 & & & \\
\hline \multicolumn{6}{|l|}{ Religion } \\
\hline Hindu & 86.9 & 13.1 & $11.857^{*}$ & 0.003 & 0.154 \\
\hline Christian & 85.7 & 14.3 & & & \\
\hline Buddhism & 53.8 & 46.2 & & & \\
\hline Others & 75.0 & 25.0 & & & \\
\hline \multicolumn{6}{|l|}{ Years of Stay } \\
\hline Below 5 yrs & 68.4 & 31.6 & $15.668^{*}$ & 0.001 & 0.177 \\
\hline 5 to $10 \mathrm{yrs}$ & 79.1 & 20.9 & & & \\
\hline 10 to $15 \mathrm{yrs}$ & 80.0 & 20.0 & & & \\
\hline Above 15 yrs & 89.1 & 10.9 & & & \\
\hline \multicolumn{6}{|c|}{ Occupational Status } \\
\hline Business & 92.1 & 7.9 & 10.324 & 0.112 & 0.144 \\
\hline Student & 83.1 & 16.9 & & & \\
\hline Farming & 87.5 & 12.5 & & & \\
\hline Employee & 85.0 & 15.0 & & & \\
\hline Unemployed & 80.6 & 19.4 & & & \\
\hline Housewife & 76.6 & 23.4 & & & \\
\hline Others & 80.0 & 20.0 & & & \\
\hline \multicolumn{6}{|c|}{ Social Interaction by Income Status of Host Community } \\
\hline Below 10,000 & 83.5 & 16.5 & 2.534 & 0.469 & 0.081 \\
\hline 10,001 to 25,000 & 89.8 & 10.2 & & & \\
\hline 25,001 to 50,000 & 85.9 & 14.1 & & & \\
\hline Above 50,000 & 87.8 & 12.2 & & & \\
\hline
\end{tabular}

${ }^{*}$ means the test statistic is significant at $5 \%$ level of significance ( $p$-value $\left.<0.05\right)$

Overall, the results depict that both the host and refugee community have benefitted from their economic ties in the study area. Furthermore, it is found that the local residents have benefitted more from the economic interactions. Hence, the Tashi Palkhiel Tibetan camp has helped in business initiatives of local people as well as provided employment opportunities.

\section{Conclusion}

The findings reveal that there exists social harmony, mutual co-existence, and bonding between the Tibetan refugees and local residents of Hemja. The two communities involve in social exchange and participate in social events of each other. The social acceptance is revealed from the fact that the practice of intermarriages between the communities is also prevalent. The Tibetan refugee camp is found not to adversely impact the host community culture. Similarly, the refugee settlement has not brought any adverse effect on the local environment. The basic services and facilities like education and health is available on equitable basis to both the communities. Finally, the economic interaction between the communities has resulted in mutually beneficial economic condition for both in terms of increased business and employment opportunities. Moreover, the 
economic benefits to the host community is relatively higher due to the refugee settlement. Overall, the findings reveal that Tashi Palkhiel Tibetan camp has positive impact on social, environmental and economic condition of the host community. The study selects only one Tibetan camp among twelve camps operating in Nepal. The study results will be more generalizable if more camps are included in the study. The study is based on opinion survey of only the local residents. Future studies can explore the issue by incorporating the perspectives

of the Tibetan refugees. Additionally, the study is based on quantitative research approach. In order to get better insights on the research issue, qualitative approach can be more appropriate. Inclusion of further dimensions of social, economic and environmental issues in the research study can offer more insightful findings in order to understand the phenomena.

Acknowledgement: This article is the product of Faculty Research Award funded by University Grants Commission (UGC), Nepal in the year 2016.

\section{References}

Adisa, J. (1996). Rwandan Refugees and Environmental Strategy in the Great Lakes Region. A Report on the Habitat/UNEP Plan of Action. Journal of Refugee Studies, 326-334.

Alexander, A. (2010). Without Refuge: Chin Refugees in India and Malaysia. Retrieved from http://www. fmreview.org/FMRpdfs/FMR30/36-37.pdf

Alix-Garcia, J. (2007). The Effect of Refugee Inflows on Host Country Populations: Evidence fromTanzania. Retrieved from http:// irnegotiation0708.pbworks.com/f/SSRNid836147.pdf

Barth, F. (1994). Ethnic Groups and Boundaries. Retrieved from http://isites.harvard.edu/fs/ docs/icb.topic446176.files/Week_4/Barth_ Introduction_Et hnic_Groups_and_Boundaries_. pdf

Betts, A. (2006). Comprehensive Plans of Action: Insights from CIREFCA and the Indochinese CPA. Retrieved from http://www.unhcr.org/43eb6a152. pdf

Black, R., \& Sessay, M. (1998). Forced Migration, Natural Resource Use and Environmental Change: The Case of the Senegal River Valley. International Journal of Population Geography, 31-47.

Buscher, D., \& Heller, L. (2008). DesperateLives: Urban Refugee Women in Malaysia and Egypt. Retrieved from http://www.fmreview.org/en/ urban-displacement/20-21.pdf 
Ecology, N. A. (2010). Socio-economic and Environmental Impacts of Dadaab Refugee Camps on Host Communities. Retrieved from https://www.drc.dk/media/2108214/socioeconomic-environmental-impact-study- of-thedadaab-refugee-camp-on-the-host-community. pdf

Finnström, S. (2003). Living with bad surroundings: war andexistentialuncertainty in Acholiland, Northern Uganda (Doctoral dissertation, Acta Universitatis Upsaliensis). http://www.diva-portal.org/smash/ record.jsf?pid $=$ diva $2 \% 3 \mathrm{~A} 163495 \&$ dswid $=-4457$

Hakovirta, H. (1988). The Global Refugee Problem: A Model and Its Application. International PoliticalScience Review (1993), 35-57.

Hamza, B. M. (2006). A report on the Somali remittance sector in Canada: Prepared for Nathanson Centre for the Study of Organized Crime and Corruption. Retrieved from https:/www.library.yorku.ca/ find/Record $/ 2036598$

Jacobsen, K. (1996). Factors Influencing the Policy Responses of Host Governments to Mass Refugee Influxes. The International Migration Review, 655-678. Retrieved from europepmc. org/abstract/MED/12292015

Kandoh, M. M. (2012). Forced Migration: Socioeconomic Implications for Hosts Communities in Southern and Northern Ghana. Retrieved from www.hioa.no/content/download/17625/190127/ file/MorforKandoh.pdf

Martin, A. (2005). Environmental Conflict Between Refugee and Host Communities. Journal of Peace Research, 329-346.

Maystadt, J.-F., \& Verwimp, P. (2009). Households in Conflict Network (Working Paper 60): Winners and Losers among a Refugee-Hosting. The Institute of Development Studies - at the University of Sussex - Falmer - Brighton - BN1 9RE. Retrieved from http://www.hicn.org/ wordpress/wp-content/uploads/2012/06/wp60. pdf

Miller, S. D. (2018). Assessing the Impacts of Hosting Refugees. Centre for International Governance Innovation World Refugee Council , 1-13.

Mills, E. J., Singh, S., Holtz, T. H., Chase, R. M., Dolma, S., Barbara, J. S., et al. (2005). Prevalence of mental disorders and torture among Tibetan refugees: A systematic review. BMC International Health and Human Rights, 1-8.

Mekuria, W. (2013). The Socio-Economic Impact of South Sudanese refugees on the Host Community in Ethiopia: the Case of Pugnido Refugee Camp: Pugnido, Gambella Region. Retrieved from http://etd.aau.edu.et/ bitstream/123456789/6051/1/13.\%20Woenu\%20 Mekuria.pdf

NUCRA. (2010). Refugees in Nepal: A Short Glimpse. Leaflet

Omeokachie, I. V. (2014). The Security implications of the refugee situation in South Africa. MA Thesis, University of Pretoria).Retrieved from https://repository.up.ac.za/bitstream/ handle/2263/41367/Omeokachie_Security_2014. pdf? sequence $=1$

Paljor, T. (2007). Current Situation of Tibetan Refugees in Exile. Retrieved from geography.org.uk/ download/GA_Conf07Paljor.doc

Pini, J. (2008). Political Violence and the African Refugee Experience. International Affairs Review. Retrieved from http://www.iar-gwu.org/node/19

Schmeidl, S. (1997). Exploring the Causes of Forced Migration: A Pooled Time-Series Analysis, 1971-1990. Social Science Quarterly, 284-308.

Smith, M. P. 2001 "Preface." In New Approaches to Migration? Transnational Communities and the Transformation of Home. Ed. N. Al-Ali and K. Koser. London: Routledge. 
TJC. (2002). Tibet's Stateless Nationals: Tibetan Refugees in Nepal. Retrieved from http://www. tibetjustice.org/reports/nepal.pdf

UNHCR. (1997). Economic and Social Impacts of Massive Refugee Populations on Host Developing Countries, as well as other Countries. Standing Committee. UNHCR, EC/47/SC/CRP.7. Retrieved from https://www.unhcr.org/excom/ standcom/3ae68d0e10/social-economic-impactlarge- refugee-populations-host-developingcountries.html

Werker, E. (2007). Refugee Camp Economies. Journal of Refugee Studies. Retrieved from http://www.humanitarianinnovation.com/ uploads/7/3/4/7/7347321/werker_2007.pdf

Whitaker, B. E. (1999). Changing opportunities: Refugees and Host Communities in Western Tanzania. Retrieved from http://www.unhcr.org/3ae6a0c70. pdf
Whitaker, B. E. (2002). Refugees in Western Tanzania: The Distribution of Burdens and Benefits Among Local Hosts. Journal of Refugee Studies. Retrieved from https://clas-pages.uncc.edu/bethwhitaker/files/.../whitaker-JRS-2002.pdf

Zetter, R. (1995). Incorporation and Exclusion: The Life Cycle of Malawi's Refugee Assistance Program. World Development, Key: citeulike:8953803, 1653- 1667.

Zetter, R., \& Deikun, G. (2010). Meeting Humanitarian Challenges in Urban Areas: Migration Review issue. Retrieved from file://E:/course/onsite\%20 sanitation/zetter-deikun-05-07.pdf 